\title{
The Effect of Humidity on the Reliability of a Surface Micromachined Microengine
}

\author{
Danelle M. Tanner, Jeremy A. Walraven, Lloyd W. Irwin, Michael T. Dugger, \\ Norman F. Smith, William P. Eaton, William M. Miller, and Samuel L. Miller \\ Sandia National Laboratories, P.O. Box 5800, MS 1081, Albuquerque, NM 87185-1081 \\ http://www.mdl.sandia.gov/Micromachine \\ email: tannerdm@sandia.gov
}

\begin{abstract}
Humidity is shown to be a strong factor in the wear of rubbing surfaces in polysilicon micromachines. We demonstrate that very low humidity can lead to very high wear without a significant change in reliability. We show that the volume of wear debris generated is a function of the humidity in an air environment. As the humidity decreases, the wear debris generated increases. For the higher humidity levels, the formation of surface hydroxides may act as a lubricant.

The dominant failure mechanism has been identified as wear. The wear debris has been identified as amorphous oxidized silicon. Large slivers (approximately 1 micron in length) of debris observed at the low humidity level were also amorphous oxidized silicon. Using transmission electron microscopy (TEM), we observed that the wear debris forms spherical and rod-like shapes.

We compared two surface treatment processes: a fluorinated silane chain, (FTS) and supercritical $\mathrm{CO}_{2}$ dried $\left(\mathrm{SCCO}_{2}\right)$. The microengines using the $\mathrm{SCCO}_{2}$ process were found to be less reliable than those released with the FTS process under two humidity levels.
\end{abstract}

\section{INTRODUCTION}

Reliability studies and predictions are becoming crucial to the success of MicroElectroMechanical System (MEMS) as commercial applications are developed. There have been extensive reliability studies by Maudie et al. identifying possible failure mechanisms in MEMS pressure sensors [1] and sensors exposed to harsh environments [2]. The lifetime experiments of Texas Instruments' Digital Micromirror Device (DMD) investigated unique failure mechanisms [3]. The DMD projection system has an array of hinged mirrors and has demonstrated $1.7 \times 10^{12}$ mirror cycles with no hinge fatigue failures. However, most of the MEMS products on the market are sensors (pressure, acceleration, and chemical) that do not have rubbing surfaces. In both sensors and the DMD example, issues like friction and wear are minimal.

For many MEMS devices, especially actuators, normal operation requires surfaces to come into contact and rub against one another. In these cases wear of the rubbing surfaces becomes a reliability issue. One of the first experiments [4] to show wear as a dominant failure mechanism ran polysilicon microturbines [5] and gears at rotational speeds up to $600,000 \mathrm{rpm}$. A focused air jet directed at the turbine induced the rotation. Gabriel et al. [4] estimated dynamic coefficients of friction between polysilicon and silicon ranging in value from 0.25 to 0.35 . The wear was extensive enough to cause misalignment followed by wedging of the device.

In another experiment, microfabricated radial-gap electric motors were tested in room air at speeds between 200 and $2000 \mathrm{rpm}$ [6]. Lifetime was limited by wear to 10,000 cycles. This experiment incorporated a silicon nitride film in the bearing and measured a coefficient of friction of the nitride-polysilicon bearing to be 0.36 . Scanning electron microscopy (SEM) analysis after failure revealed wear particles on the friction bearing surfaces.

Previous experiments [7] on the lifetime of a surfacemicromachined microengine [8] investigating frequency dependence revealed wear as the dominant failure mechanism. The median cycles to failure ranged from $10^{5}$ to $10^{6}$ with several microengines reaching close to $10^{9}$. A predictive reliability model for the microengine was developed which was based on the fundamental principles of the physics of wear in a mechanically resonating system. In another study of the microengine, it was determined that the introduction of an additional source of rubbing surfaces (in this case, a dimple rubbing against a shuttle) reduced the lifetime and thus, the reliability of the microengine [9].

The objective of the present study is to determine the fundamental correlation between environmental humidity and the lifetime of the microengine. Our previous work $[7,9]$ with microengines was performed in ambient conditions, typically $30 \%$ to $40 \%$ relative humidity. A secondary objective was to investigate the role of two different surface treatment processes and their impact on microengine reliability. These processes will be discussed in the next section.

\section{EXPERIMENTAL APPROACH}

\section{Sample Preparation}

Surface micromachined MEMS are mechanical structures fabricated from deposited thin films. The structures are encased in sacrificial layers (typically $\mathrm{SiO}_{2}$ ) until ready for use. The oxide film is etched by hydrofluoric acid (HF) to yield a "released" sample. There are several strong adhesive forces that act on the structures during the drying stage of the release [10]. These include capillary, electrostatic, and van der Waals. Capillary forces dominate at these dimensions and processes have been developed to reduce or eliminate the forces for successful operation of the MEMS structure [11].

Coupling agent coatings such as alkysilanes have been used to increase the hydrophobicity of the polysilicon surface, thus eliminating capillary forces [12]. The most studied silane coatings deposited on silicon are octadecyltrichlorosilane (OTS) precursor 


\section{DISCLAIMER}

This report was prepared as an account of work sponsored by an agency of the United States Government. Neither the United States Government nor any agency thereof, nor any of their employees, make any warranty, express or implied, or assumes any legal liability or responsibility for the accuracy, completeness, or usefulness of any information, apparatus, product, or process disclosed, or represents that its use would not infringe privately owned rights. Reference herein to any specific commercial product, process, or service by trade name, trademark, manufacturer, or otherwise does not necessarily constitute or imply its endorsement, recommendation, or favoring by the United States Government or any agency thereof. The views and opinions of authors expressed herein do not necessarily state or reflect those of the United States Government or any agency thereof. 


\section{DISCLAIMER}

Portions of this document may be illegible in electronic image products. Images are produced from the best available original document. 


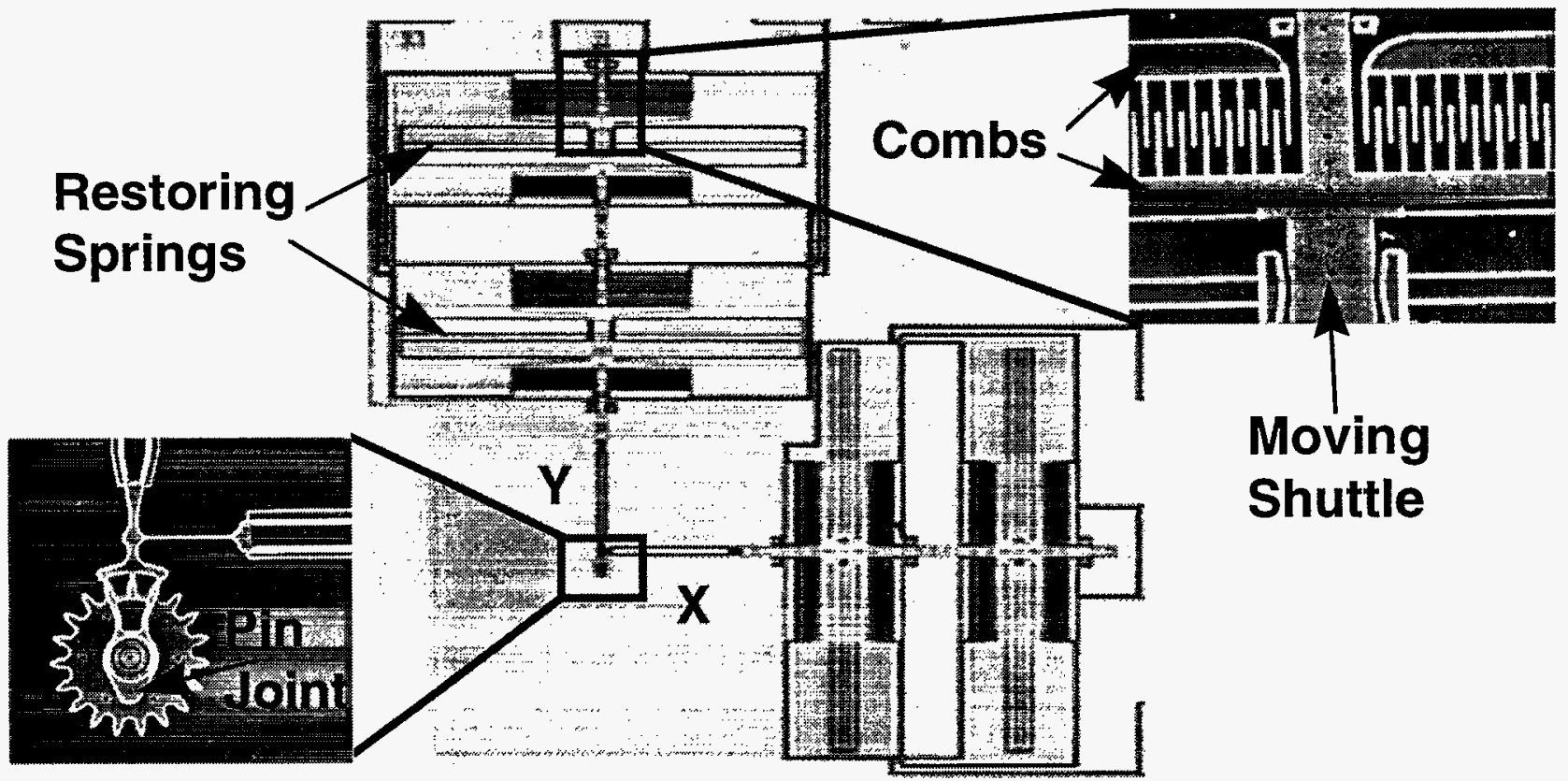

Figure 1. Sandia microengine with expanded views of the comb drive (top right) and the rotating gear (bottom left).

molecules having a chemical formula of $\mathrm{C}_{18} \mathrm{H}_{37} \mathrm{SiCl}_{3}$. Additionally, a fluorinated chain, perfluorodecyltrichlorosilane (FTS, $\mathrm{C}_{6} \mathrm{~F}_{13} \mathrm{CH}_{2} \mathrm{SiCl}_{3}$ ), has been studied by Alley et al. [13]. Application of a coupling agent requires preparation of the polysilicon surface by an oxidation step $\left(\mathrm{H}_{2} \mathrm{O}_{2}\right)$, resulting in an oxide layer a few nanometers thick.

An alternate approach to applying a coupling agent prevents the formation of a meniscus by eliminating the liquid phase in the drying process. This method is supercritical $\mathrm{CO}_{2}$ drying [14] and it has been successfully applied to surface micromaching.

In these experiments we used samples that had either an FTS surface treatment or samples that were supercritically dried $\left(\mathrm{SCCO}_{2}\right)$. The $\mathrm{SCCO}_{2}$ samples had no specific oxidation step, but were in an air environment that would promote growth of a native oxide.

\section{Microengine Lifetime Experiment}

This study used the electrostatically driven microactuator (microengine) developed at Sandia National Laboratories [8]. The microengine consists of orthogonal linear comb drive actuators mechanically connected to a rotating gear as seen in Figure 1. By applying voltages, the linear displacement of the comb drives was transformed

Table 1. Series of humidity experiments performed.

\begin{tabular}{|l|l|l|}
\hline $\begin{array}{c}\text { Humidity } \\
\left(\% \mathbf{R H} @ \mathbf{2 5}^{\circ} \mathbf{C}\right)\end{array}$ & $\begin{array}{c}\text { Surface } \\
\text { Treatment }\end{array}$ & $\begin{array}{c}\text { \# Parts } \\
\text { Tested }\end{array}$ \\
\hline 1.8 & FTS & 28 \\
\hline 1.8 & FTS & 30 \\
\hline 10 & FTS & 44 \\
\hline 24 & FTS & 29 \\
\hline 31 & FTS & 29 \\
\hline 39 & FTS & 22 \\
\hline 68 & FTS & 31 \\
\hline 1.8 & SCCO $_{2}$ & 16 \\
\hline 31 & SCCO $_{2}$ & 33 \\
\hline
\end{tabular}

into circular motion. The $\mathrm{X}$ and $\mathrm{Y}$ linkage arms are connected to the gear via a pin joint. The gear rotates about a hub, which is anchored to the substrate.

A die with four microengines was designed and fabricated for this experiment. There was one gearless microengine on the module for setup and calibration purposes, but it was not run in the experiment. The dice were packaged with taped glass covers to prevent particle contamination during handling. The packages were then stored in a dry nitrogen environment prior to testing. The covers were removed during the test to expose the microengines to the local environment. The Sandia High Volume Measurement of Micromachine Reliability (SHiMMeR) [15] tester was used to provide electrical signals to large numbers of packaged microengines and to optically inspect them for functionality.

A humid environment was achieved by bubbling laboratory compressed air through a large bottle of deionized water. The humid air that exited the bottle was then piped into the environmental chamber surrounding the packaged parts. A humidity sensor located inside the chamber controlled the airflow to maintain humidity levels to within $\pm 1 \% \mathrm{RH}$ at $25^{\circ} \mathrm{C}$. A General Eastern humidity monitor (Model HYGRO M4) using chilled mirror technology measured the dew point. All dew point values were converted to percent relative humidity at $25^{\circ} \mathrm{C}$. We performed lifetime tests at six humidity levels, $1.8 \%, 10 \%, 24 \%, 31 \%, 39 \%$, and $68 \% \mathrm{RH}$ at $25^{\circ} \mathrm{C}$ for the FTS coated devices and two humidity levels, $1.8 \%$ and $31 \% \mathrm{RH}$ at $25^{\circ} \mathrm{C}$ for the $\mathrm{SCCO}_{2}$ devices as shown in Table 1.

For each test, we operated the microengines with the same drive parameters at a frequency of $1720 \mathrm{~Hz}$, slightly higher than the resonant frequency of $1500 \mathrm{~Hz}$. We have found that operation near resonance causes increased wear [7]. The microengines were stressed with large drive forces to accelerate the failure times. The stress intervals followed roughly the same sequence for all the experiments. The sequence was $2000,4000,8000,16000, \ldots$, rotation cycles of the drive gear per stress interval. If more than 4 parts failed during a particular stress interval, we stressed the microengines for the same number of cycles as the previous interval to achieve better resolution in the number of cycles to failure. The devices were stressed at high speed and then slowed to $1 \mathrm{~Hz}$ to inspect for functionality. A failure was defined as the inability of the microengine drive gear to make a complete revolution at the $1 \mathrm{~Hz}$ inspection 
speed. During the inspection interval, we noted any observed changes or degradation in the motion of the gears for our records.

\section{DATA ANALYSIS}

Because the parts were observed at fixed inspection times, common to all the parts, the results fall into the category of reliability data called "interval" data. Reliability analysis of interval data typically uses either the Weibull or lognormal statistical distributions to fit the data. Both distributions work quite well. However, the choice of the distribution should be based on the failure mechanism the data is describing. The Weibull is an extreme value or "weak link" distribution that applies when many small defect sites compete with each other to be the one that causes the earliest failure. The lognormal distribution is based on a proportional growth model, where at any instant in time, the process undergoes a random increase in degradation that is proportional to its present state [16]. The multiplicative effect of all these random growth events build up to failure. The microengine failures are known to be due to an accumulation of wear debris and hence, the lognormal distribution represents the best choice based on the physics of failure.

The first step in the data analysis was ordering the data from low to high values of accumulated cycles to failure. We then plotted the accumulated number of cycles to failure against the cumulative percent failure for each humidity level. A linear regression of the lognormal data resulted in an estimate of $t_{50}$, the median cycles to failure. The estimate for the lognormal shape parameter, $\sigma$, was also determined.

The data from each of the experiments could be described by a simple unimodal distribution such as seen in Figure 3. The regression analysis yielded a median of $4 \times 10^{5}$ cycles to failure with a correlation coefficient of 0.98 . The shape parameter, $\sigma$, was determined to be 0.2 . The above analysis was completed for each experiment and a value for the median and sigma of each distribution was calculated. We performed nine experiments during which a total of 262 parts failed. A larger number of experiments were performed with the FTS process simply because of their greater availability.

Table 2 has the results of lognormal fits to all of the humidity experiments. The data is also graphically represented in Figure 4 with $95 \%$ confidence bounds represented by error bars. The figure shows a rather flat dependence on humidity for the FTS-coated microengines with the exception near $0 \%$. The $\mathrm{SCCO}_{2}$ data shows the failure roughly an order of magnitude earlier, indicating a less reliable microengine.

The behavior of the microengines tested at levels of $10 \% \mathrm{RH}$ and above followed a consistent pattern. Initially the microengines

Table 2. Results of median number of cycles to failure from all humidity experiments performed.

\begin{tabular}{|l|l||c|r||}
\hline $\begin{array}{c}\text { Humidity } \\
\left(\% \mathbf{R H} @ \mathbf{2 5}^{\circ} \mathbf{C}\right)\end{array}$ & $\begin{array}{c}\text { Surface } \\
\text { Treatment }\end{array}$ & \multicolumn{2}{c|}{ Median and sigma } \\
\hline & & $t_{50}$ & $\sigma$ \\
\hline 1.8 & FTS & $9.60 \mathrm{E}+05$ & 0.107 \\
\hline 1.8 & FTS & $1.07 \mathrm{E}+06$ & 0.196 \\
\hline 10 & FTS & $2.67 \mathrm{E}+05$ & 0.3 \\
\hline 24 & FTS & $3.51 \mathrm{E}+05$ & 0.22 \\
\hline 31 & FTS & $3.70 \mathrm{E}+05$ & 0.39 \\
\hline 39 & FTS & $4.00 \mathrm{E}+05$ & 0.16 \\
\hline 68 & FTS & $1.99 \mathrm{E}+05$ & 0.11 \\
\hline 1.8 & SCCO $_{2}$ & $1.40 \mathrm{E}+05$ & 0.37 \\
\hline 31 & SCCO $_{2}$ & $3.98 \mathrm{E}+04$ & 0.69 \\
\hline
\end{tabular}

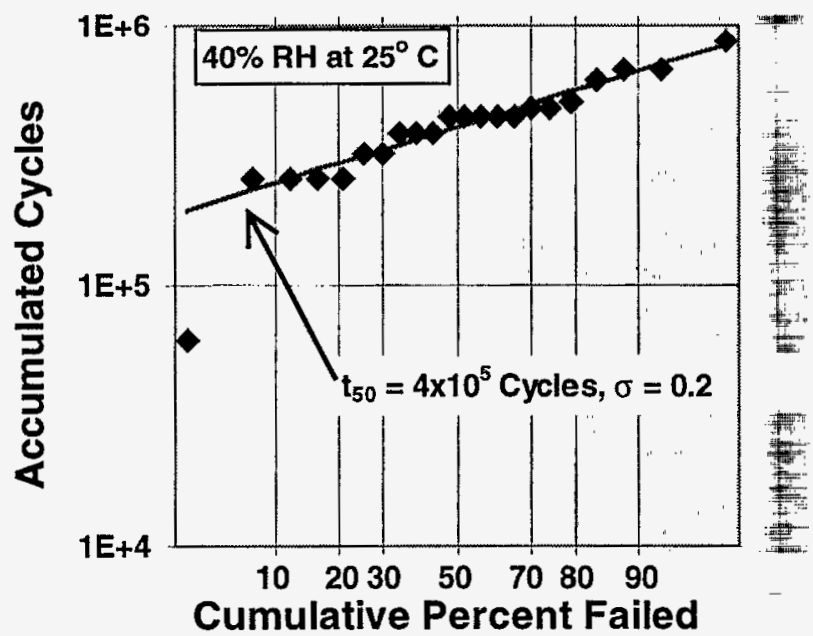

Figure 3. Lognormal distribution of accumulated cycles to failure for the $40 \%$ RH stress. The early failure, with less than $10^{5}$. cycles, was omitted from the regression analysis.

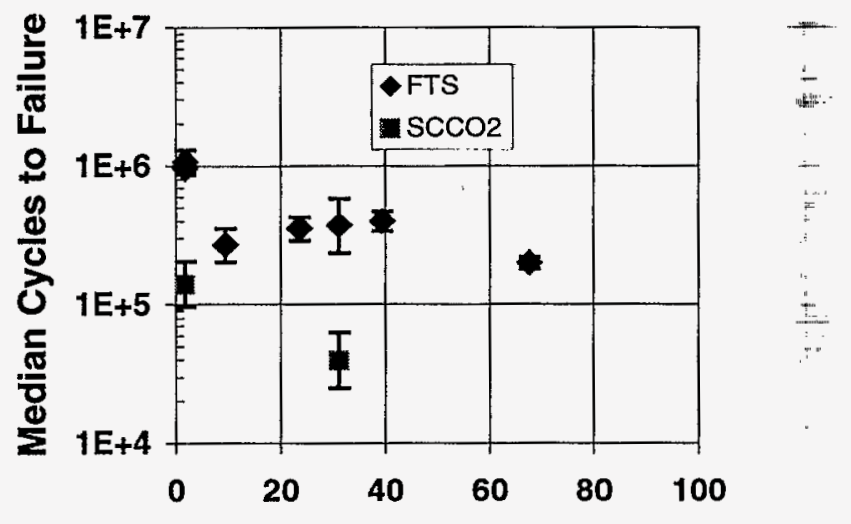

$\%$ Relative Humidity at $25^{\circ} \mathrm{C}$

Figure 4. The effect of humidity on the lifetime of the microengines shows a rather flat distribution with the exception near $0 \%$. The y error bars represent $95 \%$ confidence bounds. The microengines were stressed with large forces to accelerate failures in these experiments.

ran smoothly. With the accumulation of cycles, the operation of the microengines became sticky and jerky (stick-slip behavior) at inspection frequencies. Some of the microengines would actually work through the sticky behavior and become smooth again. Near the end of life, the rotation became more erratic until the microengine failed by sticking, rocking back and forth through a small angle, or breaking a pin joint. We observed broken pin joints (connects the linkage arm to the gear as shown in Figure 1) in only $6 \%$ of the failures for devices at levels of $10 \% \mathrm{RH}$ and above. There were no broken pin joints in the $\mathrm{SCCO}_{2}$ experiment at $31 \% \mathrm{RH}$.

The values shown in Figure 4 are comparable to previous data used in the development of a predictive reliability model based on the fundamental principles of wear coupled to a resonating system $[7,9]$. In this work, the stickiness of the gear motion was attributed to the interaction of asperities on the rubbing surfaces. Asperities could break off causing wear debris or adhere which would result in a seized gear. 
A contributing factor to failure values of less than $10^{6}$ cycles lies in the design of the microengines tested. It has been experimentally determined that the $Y$ comb drive "linearly clamps" during a portion of rotation of the gear [17]. The clamping was due to the force from the fringing fields at the ends of the comb fingers that occur when

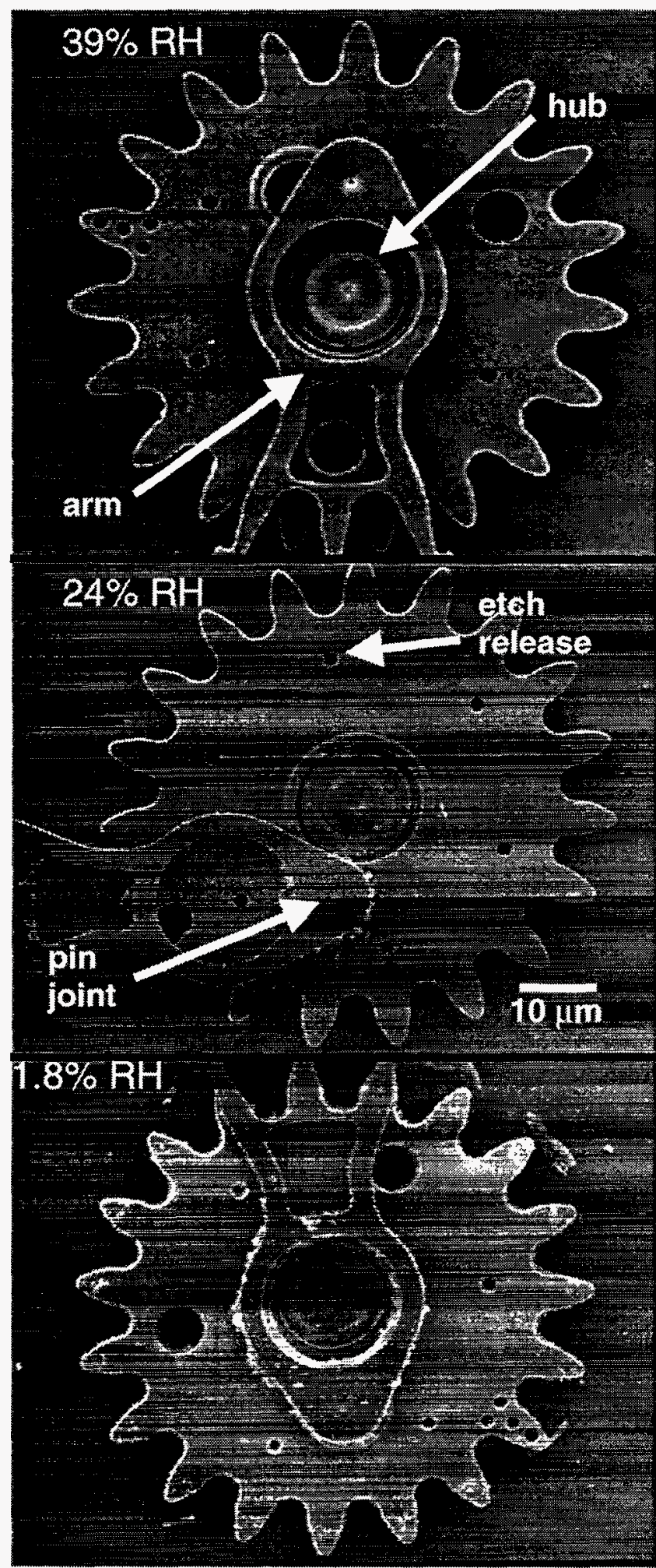

Figure 5. SEM images of various microengine gears stressed under different humidity conditions $39 \%, 24 \%$, and $1.8 \% \mathrm{RH}$ at $25^{\circ} \mathrm{C}$. The microengines were stressed for roughly the same number of cycles, but the amount of wear debris for each humidity was dramatically different. (FTS) the combs are fully engaged. This effect increased the force on the drive pin joint by an unknown amount. In addition, in order to accelerate failures the longitudinal drive signal force was five times larger than the minimum force needed to simply run the microengine.

The behavior of the microengines tested at levels near $0 \%$ was quite different. In this low humidity case, there was a dramatic increase in the amount of wear debris, regardless of the coating method. We first noticed the formation of wear debris after accumulation of roughly $10^{5}$ cycles. The debris was typically thrown out from the hub and collected on the gear face and surrounding substrate. In general, the gear hubs were worn down and the gears exhibited severe wobble during operation. In $55 \%$ of the failures ( $31 \%$ for $\mathrm{SCCO}_{2}$ ), the pin joint actually wore down and severed. We suspect that the large wear rate removes any asperities that would cause the gear to seize in the same manner as the higher humidity levels. Therefore, wear of polysilicon would continue until the pin joint is worn away, causing failure at a much higher number of cycles. The increase in median cycles to failure observed at $1.8 \%$ RH in Figure 4 resulted from this change in failure mechanism and was not a true indication of increased reliability.

\section{FAILURE ANALYSIS}

\section{Scanning Electron Microscopy (SEM)}

FTS Treatment: The dominant failure mechanism for these microengines has been identified as wear. The major effects of the wear process were either pin joint wear-out causing the linkage arm to break away from the gear or accumulation of wear debris causing the microengine to seize. The overwhelming effect of the humidity was demonstrated by the amount of wear debris observed. The volume of debris increased dramatically as we lowered the humidity. In Figure 5, we show a comparison of the gears of microengines stressed in air environments of $39 \%, 24 \%$, and $1.8 \% \mathrm{RH}$ at $25^{\circ} \mathrm{C}$ These microengines were stressed to failure at $862,000,746,000$, and 742,000 accumulated cycles, respectively, yet the microengine with the most accumulated cycles has the least amount of wear debris. In the $39 \%$ RH case, there is a small amount of debris located around the hub. The $24 \% \mathrm{RH}$ case shows more noticeable wear debris around the hub and on the linkage arm. The debris in the $1.8 \%$ case includes large slivers near the gear teeth. Debris has been thrown out and collected on the hub face, at the tips of the gears, on the linkage arm, in the etch-release holes, and onto the substrate area outside of the gear face. These images are characteristic of observations at different humidity levels.

Using a field emission SEM to further magnify and characterize the wear debris, we again noticed a difference between the $39 \%$ and the $1.8 \%$ RH case. Figure 6 shows a magnified view of the hub of a microengine that failed at 510,000 cycles at $39 \%$ RH. The box region has been magnified further to illustrate the debris morphology The wear debris appears to be 200 to $500 \mathrm{~nm}$ agglomerates which string together with other agglomerates to form chains of $1 \mu \mathrm{m}$ or longer.

For comparison, we investigated the hub of a microengine stressed to failure after 642,000 cycles in $1.8 \% \mathrm{RH}$ at $25^{\circ} \mathrm{C}$. This hub is shown in Figure 7. The first item to note (indicated by an arrow) is the radial offset in the gear and hub due to the large amount of wear between the hub and the mating gear. The offset caused a wobble in the motion of the gear at the inspection frequency of $1 \mathrm{~Hz}$. Note also that the entire hub is covered with particulate wear debris. This is shown more fully in the lower image of Figure 7, which is a higher magnification of the box region. There are no stringy agglomerates in the $1.8 \%$ RH case. 


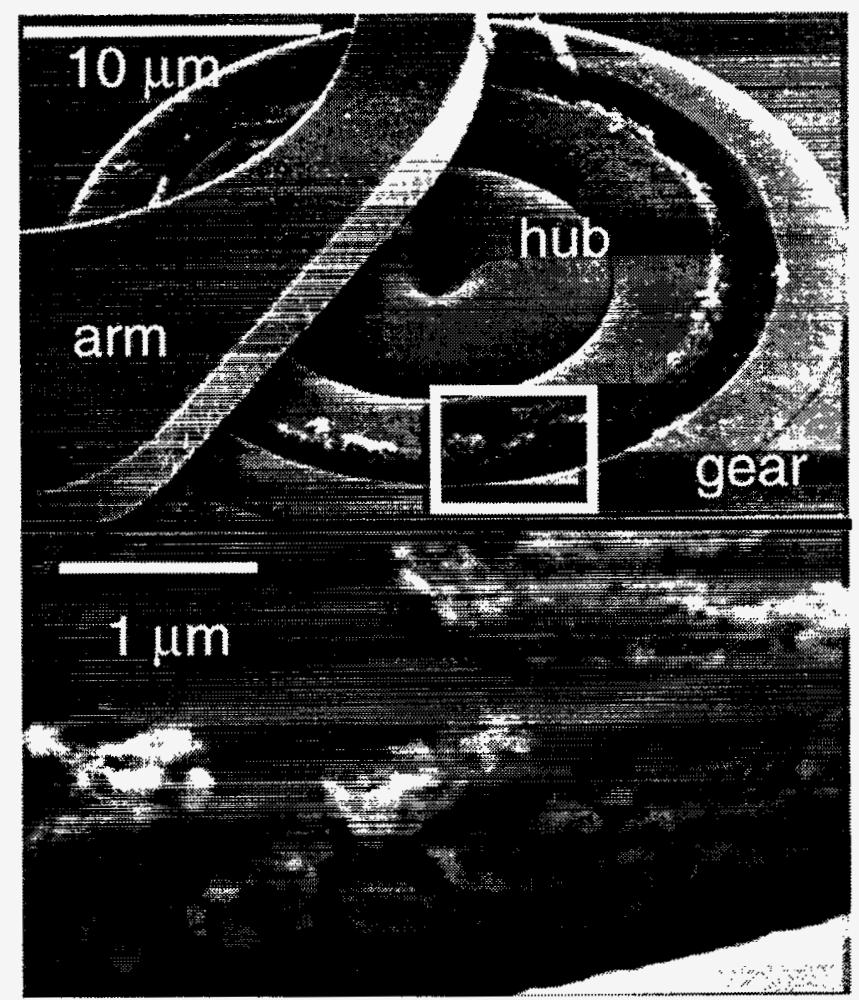

Figure 6. SEM magnified view of the hub region on a microengine that failed at 510,000 accumulated cycles during the $39 \%$ humidity test shows the morphology of the wear debris. (FTS)

$\mathrm{SCCO}_{2}$ Treatment: Just as in the FTS treatment, the dominant failure mechanism was associated with wear. As shown in Figure 8, the amount of wear debris on the face of the gear far exceeded that observed in the FTS case at the humidity level of $1.8 \% \mathrm{RH}$. This engine failed at 600,000 cycles. The gap around the hub was an indication of severe wear.

Closer examination revealed particulate wear debris in spherical and rod-like agglomerations. The $31 \% \mathrm{RH}$ experiment had very little wear debris, in part because of fewer revolutions of 510,000 cycles. The debris did not form stringy agglomerates as in the FTS case.

\section{Focused Ion Beam (FIB)}

FTS Treatment: To investigate the effect of wear, FIB cross sections were performed on a sample from each humidity level. Shown in Figure 9 are cross sections taken from a control (top), 39\% RH (middle), and $1.8 \%$ RH (bottom) samples. The control sample was tested for functionality, but was not stressed. Because debris is not shown in the control sample we believe the debris was caused by wear, not the FIB cut. The $39 \% \mathrm{RH}$ microengine was stressed to failure at 606,000 cycles and the $1.8 \%$ RH microengine was stressed to failure at 542,000 cycles. In the $39 \% \mathrm{RH}$ case, we observed mostly pin joint wear as shown with the notched diameter. The wear of the pin joint was accompanied by a reduction in the pin joint opening, probably due to a buildup of debris. For the $1.8 \% \mathrm{RH}$ experiment the wear was observed in both the pin joint and the hub. The pin joint diameter eventually broke in the majority of samples tested (32 times out of 50 samples) for the $1.8 \%$ case.

Using high resolution SEM, closer observation of the pin joint of the $10 \% \mathrm{RH}$ microengine stressed to failure at 510,000 cycles re-

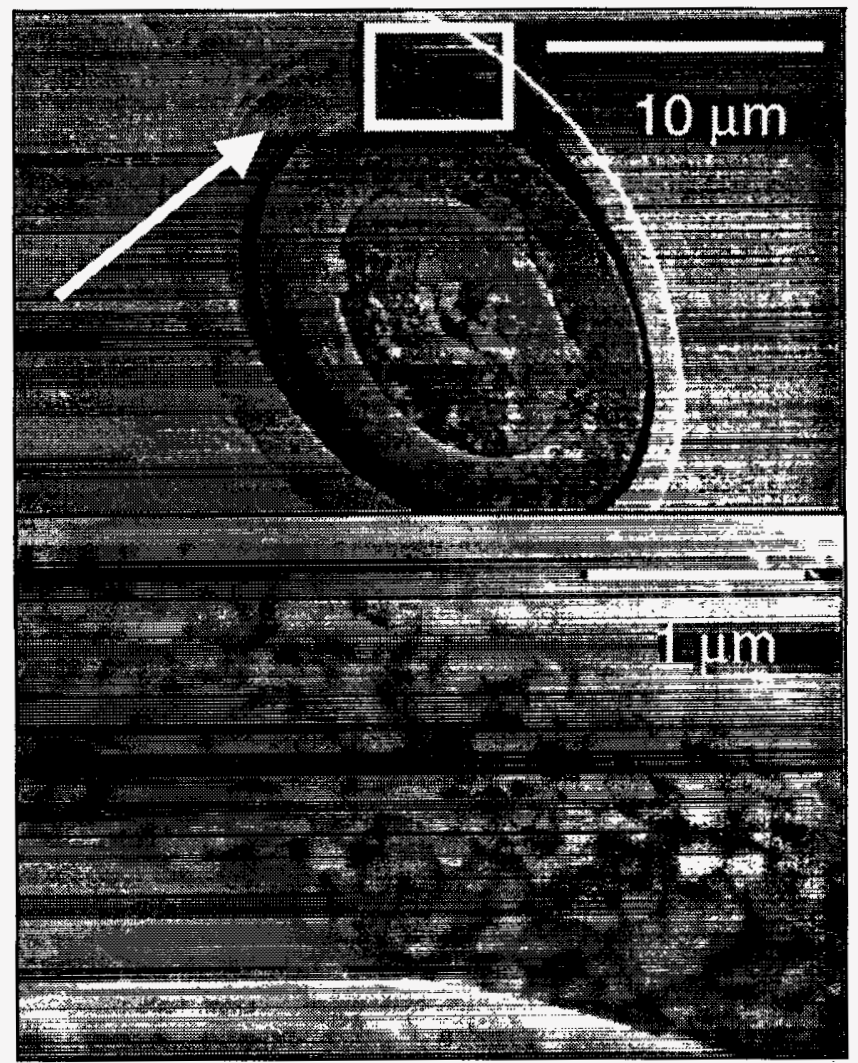

Figure 7. SEM magnified view of the inner gear region on a micToengine stressed to failure after 642,000 cycles at $1.8 \% \mathrm{RH}$. The wear debris formed particulate matter, each smaller than $100 \mathrm{~nm}$. (FTS)

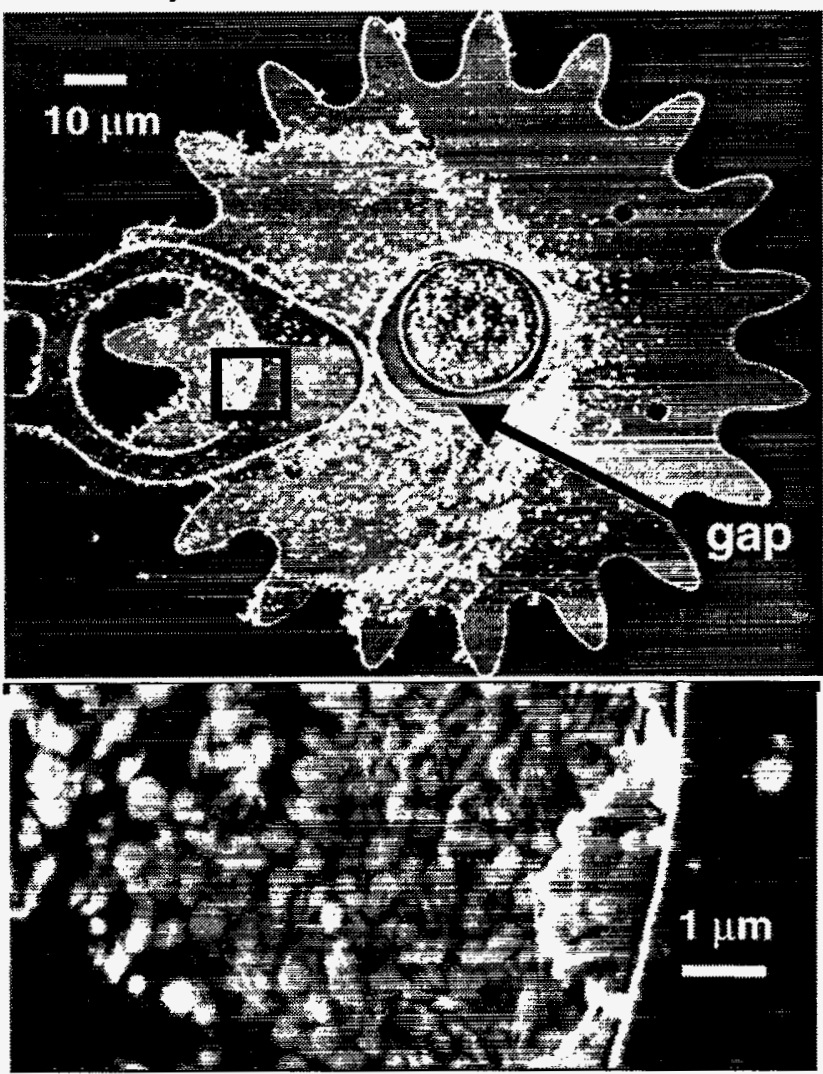

Figure 8. SEM image of a microengine that failed at $600,000 \mathrm{cy}-$ cles at $1.8 \%$ RH illustrates the wear debris produced. The gap near the hub is an indication of severe wear. Note the morphology of the wear debris in the lower magnified image. $\left(\mathrm{SCCO}_{2}\right)$ 


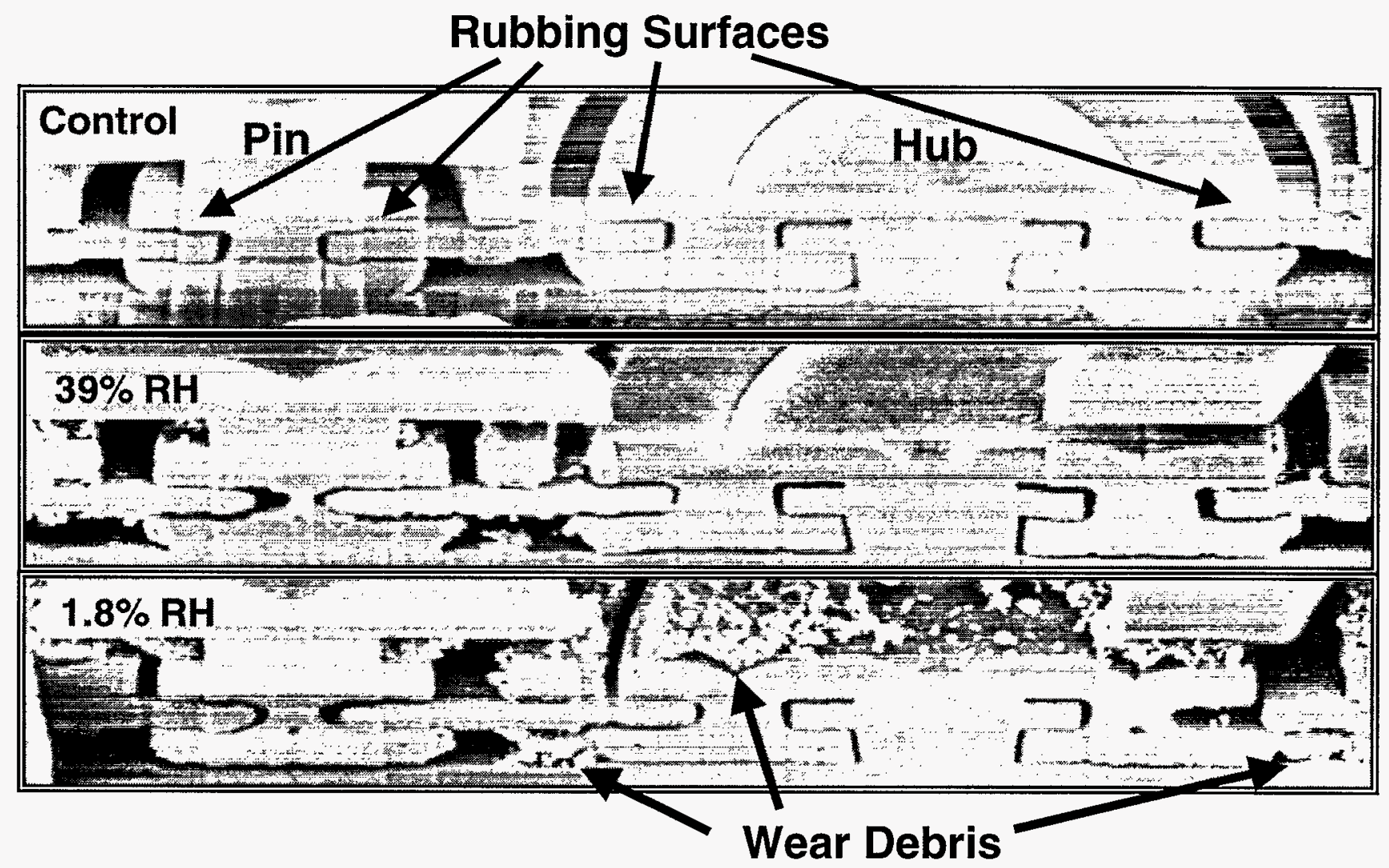

Figure 9. SEM images of the control, the $39 \% \mathrm{RH}$ sample and the $1.8 \% \mathrm{RH}$ sample illustrate the amount of wear debris created in each experiment. Arrows indicate the rubbing surfaces. In both stressed samples, the pin joint has been worn down from its fabricated $3 \mu \mathrm{m}$ diameter. (FTS)

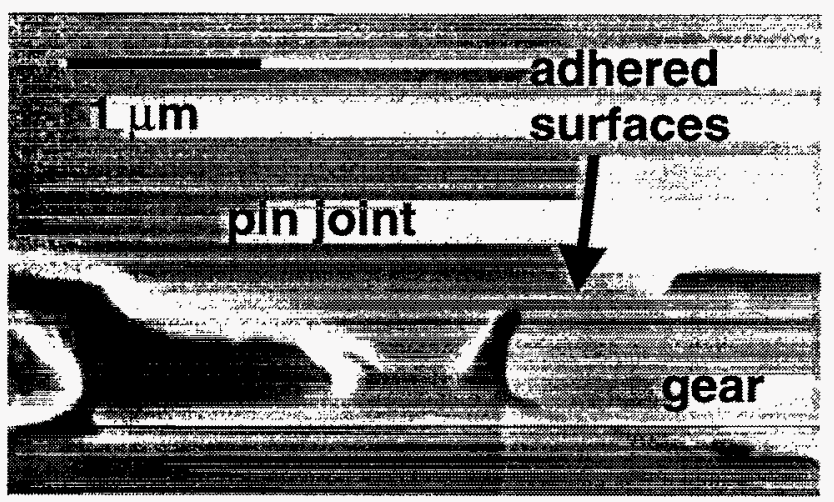

Figure 10. SEM magnified view of the pin joint region in a FIB cross section shows the area where the two surfaces adhered causing the microengine to seize. This microengine was tested at $10 \% \mathrm{RH}$ at $25^{\circ} \mathrm{C}$. (FTS)

veals adhesion of the wearing surfaces (Figure 10). This was our first observation of adhered surfaces, which yielded clear evidence of the cause of failure. As indicated on the right hand side of Figure 10 , the adhered region is approximately $0.7 \mu \mathrm{m}$ long.

\section{Transmission Electron Microscopy (TEM)}

TEM was employed to attain a better understanding of the morphology and composition of the wear debris and the gear wear sur- face. Wear debris has been studied at $1.8 \%$ and $39 \% \mathrm{RH}$ at $25^{\circ} \mathrm{C}$, using a Phillips CM30 300keV TEM with an attached energy dispersive $\mathrm{x}$-ray spectroscopy (EDS) system. Plan-view samples were prepared for analysis by using polyacetate film to remove the gear from the package. The underlying gear surface thus revealed was then coated with an amorphous carbon film. These samples were transferred to a TEM grid by removal of the polyacetate film with acetone. The adhering gear and debris were used for analysis.

Gears from two microengines tested to failure at $1.8 \% \mathrm{RH}$ were examined in plan-view. These engines accumulated 642,000 and 742,000 cycles prior to failure. As illustrated in the SEM micrograph of Figure 5, large amounts of wear debris are produced in this environment. The analysis of wear debris found outside the gear, adhering to the gear teeth, and inside etch release holes of both gears showed the debris to be either spherical or rod-like in geometry. Figure 11 shows spherical particles ranging from $100 \mathrm{~nm}$ to -250 $\mathrm{nm}$ in diameter. Also shown are rod-like debris particles with diameters ranging from 20 to $50 \mathrm{~nm}$ and lengths up to $0.5 \mu \mathrm{m}$. The morphology of both the spherical and rod-like structures was determined by tilting the wear debris along its axis through angles of $50^{\circ}$ to $60^{\circ}$. These images (not shown) did not illustrate significant deviation from either the spherical or rod-like shapes.

High resolution TEM did not indicate the formation of boundaries in larger wear particles. However, the smaller particles may have agglomerated to form the larger debris. This analysis also showed a fold or cavity in the spherical debris (not shown). When examined using $300 \mathrm{keV}$ electrons, the edges changed from an initiâl jagged appearance to a more rounded shape due to localized heating from high-energy electron bombardment. 

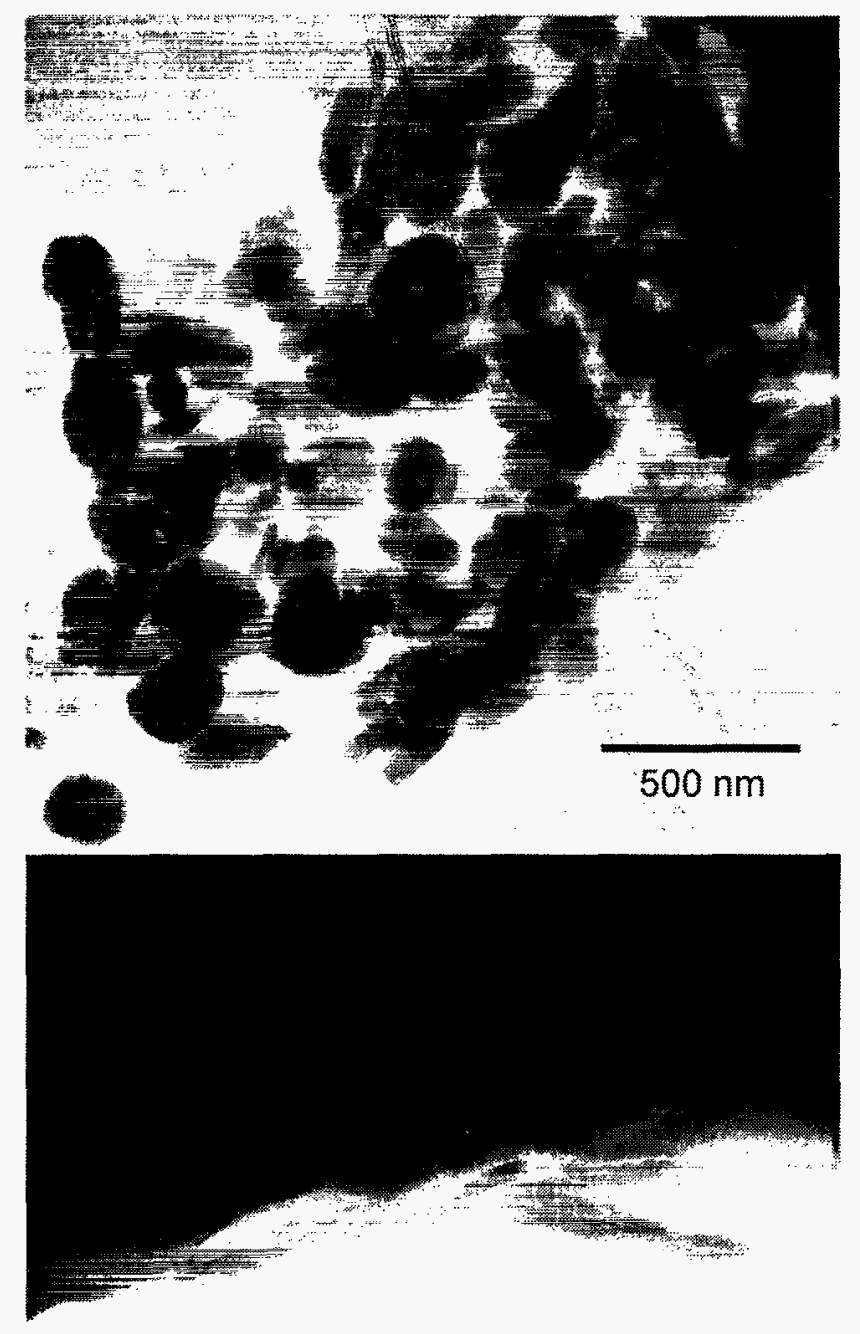

$250 \mathrm{~nm}$

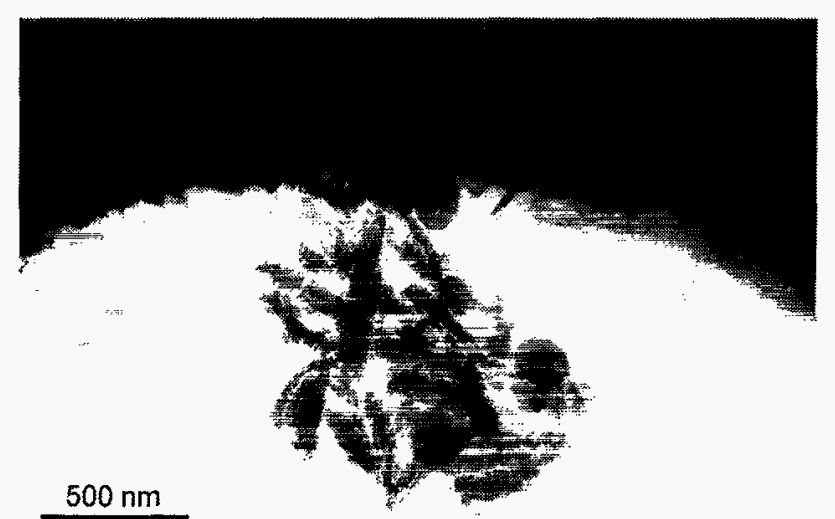

Figure 11. Spherical and rod-like debris morphologies from outside the gear (top), adhering to the gear tooth (middle) and inside an etch release hole (bottom). Note the region inside the spherical debris. (FTS)

\section{Identification of Wear Debris}

Using TEM in conjunction with EDS, the wear debris has been identified as amorphous oxidized silicon with either spherical or rodlike morphologies. EDS spectrums taken from wear debris found outside the gear, adhering to the gear teeth, and inside etch release holes revealed high concentrations of carbon, oxygen and silicon. Diffraction patterns (not shown) taken from these locations showed broad ring-like patterns typical of amorphous materials. The lack of diffraction spots or speckled rings from these areas indicate no polysilicon was worn directly away from the hub or pin joint regions during testing. Figure 12 illustrates an EDS spectrum typical of debris analyzed from all three regions. High concentrations of carbon result from the thin carbon film used for sample preparation.

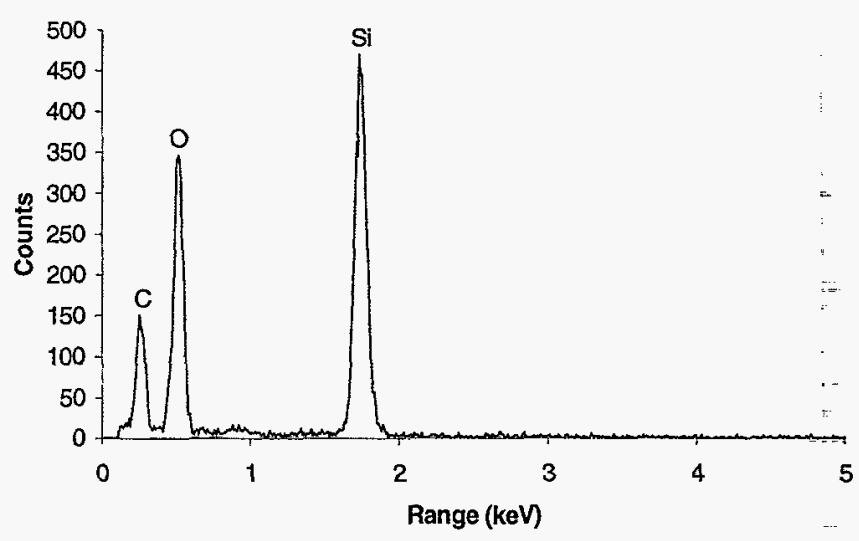

Figure 12. EDS spectra of wear debris found outside the gear. Note the strong presence of oxygen and silicon.

Although EDS indicated the elemental constituents of the wear debris, we could not distinguish the stoichiometry of oxidized silicon using this technique. Missing from the spectrum is any indication of fluorine from the FTS coating. The coating was only a few nanometers thick implying that the volume of FTS is quite small which would make the peak from fluorine indiscernible.

Large slivers of wear debris were observed on some of the microengines tested at $1.8 \%$ RH. TEM analysis of a sliver from a microengine stressed to $4,192,000$ cycles indicated that the debris was composed of agglomerates of spherical and rod-like particles. These particles maintain their morphology even with failure cycles five to ten times greater than microengines in our previous analysis. EDS in conjunction with diffraction analysis showed the presence of oxidized silicon with no indication of polysilicon. The slivers of oxidized silicon were thrown out of the hub region after severe wear had occurred.

\section{DISCUSSION}

Our experiments have shown that wear of the polysilicon surfaces contributed to the failure of the microengines. Performing these experiments in air with varying humidity introduced effects due to different surface reactions into the friction and wear study. Chemical interactions as a result of rubbing are referred to as tribochemistry and tribochemical reactions influence friction coefficients as well as wear mechanisms and wear rates [18].

We have divided the discussion into the pertinent issues of comparison of the surface treatment methods, quantifying the volume of wear, and discussing the wear debris. 
$\mathrm{SCCO}_{2}$ vs. FTS

The reliability data indicated that the $\mathrm{SCCO}_{2}$ drying process produced microengines, which were less reliable because of early failure times at both humidity levels. The difference could be due to differences in coefficient of friction (COF) between the two methods. Early work by Gabriel [4] using air-dried turbines measured the dynamic COF between polysilicon and silicon near 0.3 . Work by Srinivasan et al. [19] suggests that nanometer thick surface treatments can act as a boundary lubricant and reduce the dynamic COF between FTS-coated polysilicon surfaces to 0.08 . The normal force in Srinivasan's experiments was roughly $5 \mu \mathrm{N}$ and total number of cycles was in the $10^{5}$ to $10^{6}$ range, which is applicable to what the microengines experience.

\section{Quantifying Wear}

To estimate the wear volume of material one can either measure the volume of the wear debris or measure the missing volume in the worn device. We chose the latter and used the FIB cross sections (Figure 9) from FTS-coated devices to estimate the volume worn for the humidity levels of $1.8 \%, 10 \%, 24 \%$, and $39 \% \mathrm{RH}$ at $25^{\circ} \mathrm{C}$.

The locations exhibiting the most wear were the hub and pin joint areas so we made our estimates there. Measurements of the diameter of worn hubs, gears, and pin joints were made. The cross sectional area was calculated and compared to the control to yield a value for worn area. This value was then multiplied by the thickness to yield the volume of the material worn away. The technique assumes that the wear is symmetrical around the hub and pin joint. We estimated the error in the technique as $\pm 20 \%$ of the calculated worn area. The wear volume was normalized by the total number of cycles to failure to yield wear rate which is shown in Figure 13 as a function of $\% \mathrm{RH}$ at $25^{\circ} \mathrm{C}$.

The wear rate shown in Figure 13 agrees with studies of a $\mathrm{SiC} / \mathrm{SiC}$ system [20] where the decrease in wear rate has been attributed to a tribochemical reaction leading to the formation of a protective film of hydrated amorphous silica. Silicon nitride sliding on silicon nitride was also investigated [21] and the main mechanism of wear was the tribochemical oxidation of the silicon nitride to form silicon oxide. The wear rate increased in drier conditions in the silicon nitride case also.

For the case of polysilicon sliding on polysilicon, Mizuhara and Hsu [22] reported the formation of surface hydroxides which may protect the surface from additional wear at high humidity. In this case, the mechanical wear produced dangling silicon bonds. Water reacted with this surface to form $\mathrm{Si}-\mathrm{OH}$ and $\mathrm{Si}-\mathrm{H}$. Zanoria et al. [23] also reported that the rubbing-enhanced reaction of $\mathrm{Si}$ with water vapor generated Si-OH groups. The mechanism of $\mathrm{Si} \rightarrow \mathrm{SiOH} \rightarrow$ $\mathrm{SiO}_{2} \rightarrow$ hydrated $\mathrm{SiO}_{2}$ provided a lubricating film to protect the surface [24].

\section{Wear Debris Formation}

Wear debris typically forms when asperities from the sliding surfaces contact and break [25]. The localized temperature at the asperity (flash temperature) was elevated. Whether that temperature was high enough to accelerate oxide growth is uncertain. Because of the large presence of oxidized silicon and the absence of crystalline polysilicon in the debris, we conclude that the material removed by wear was already oxidized by rubbing and reaction with the environment. The broken oxidized silicon asperities could then agglomerate into larger pieces throughout the cycling of the gear, forming spherical and rod-like debris. The formation of cylindrical sliding wear debris on silicon in humid conditions and elevated temperatures in macro-scale wear experiments has been observed [23].

The wear debris from higher humidity tests formed an elongated stringy agglomeration. Further analysis with TEM is planned to investigate differences in agglomerate morphology as a function of surface treatment.

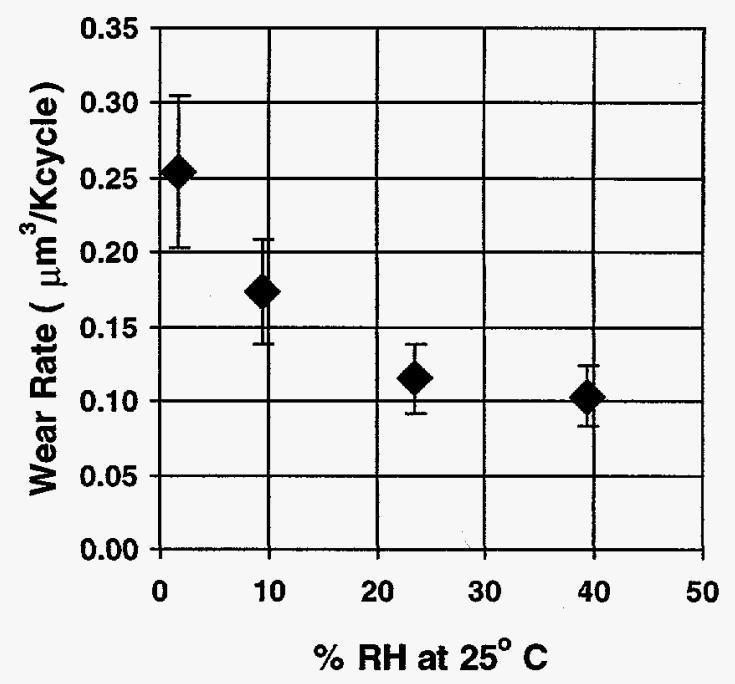

Figure 13. This plot of wear rate of FTS-coated microengines as a function of humidity shows the increase in wear rate as humidity decreases. (FTS)

\section{CONCLUSIONS}

We have shown that the amount of wear debris generated in sliding micromachined polysilicon surfaces is a function of the humidity in an air environment. As the humidity decreases, the volume of wear debris generated increases. For the higher humidity levels, the formation of surface hydroxides may act as a lubricant resulting in lower amounts of wear debris. At lower levels of humidity, $1.8 \%$ and $10 \% \mathrm{RH}$, formation of hydroxides is reduced, resulting in large amounts of wear debris.

The dominant failure mechanism has been identified as wear. The major effects of the wear process were that either the pin joint wore out causing the linkage arm to break free of the gear or the accumulation of wear debris caused mechanical interference which seized the microengine. The wear debris has been identified as amorphous oxidized silicon, both in small and large agglomerates. No polysilicon was observed in any portion of the wear debris.

The $\mathrm{SCCO}_{2}$ treatment process produced microengines that were less reliable than microengines with the FTS treatment, which can be attributed to the FTS film acting as a lubricant.

\section{ACKNOWLEDGMENTS}

The authors thank the personnel of the Microelectronics Development Laboratory at SNL for fabricating, releasing, and packaging the devices used for this test. We acknowledge the help of Karen Helgesen for acquiring the data and Alex Pimental for the FIB cuts. We thank Ken Peterson for the initial FA work. We also appreciate the work by Tom Headly for the TEM analysis. 
Sandia is a multiprogram laboratory operated by Sandia Corporation, a Lockheed Martin Company, for the United States Department of Energy under Contract DE-AC04-94-AL85000

\section{REFERENCES}

[1] T. Maudie, "Testing Requirements and Reliability Issues Encountered with Micromachined Structures," Proceedings of $2^{\text {nd }}$ International Conference on Microstructures and Microfabricated Systems, 95-27, 1995, pp. 223-230.

[2] T. Maudie, D. J. Monk, D. Zehrbach, and D. Stanerson, "Sensor Media Compatibility: Issues and Answers," Proceedings of Sensors Expo, Anaheim, CA, 1996, pp. 215-229.

[3] Douglass, M. R., "Lifetime Estimates and Unique Failure Mechanisms of the Digital Micromirror Device (DMD)," IEEE International Reliability Physics Symposium Proceedings, Reno, NV, 1998, pp. 9-16.

[4] K. J. Gabriel, F. Behi, and R. Mahadevan, "In situ Friction and Wear Measurements in Integrated Polysilicon Mechanisms," Sensors and Actuators, A21-A23, 1990, pp. 184-188.

[5] M. Mehregany, K. J. Gabriel, and W. S. N. Trimmer, "Integrated fabrication of polysilicon mechanisms," IEEE Trans. Electron Devices, ED-35, 1999, pp. 719-723.

[6] Lee S. Tavrow, Stephen F. Bart, and Jeffrey H. Lang, "Operational characteristics of microfabricated electric motors," Sensors and Actuators, A35, 1992, pp. 33-44.

[7] D. M. Tanner, W. M. Miller, W. P. Eaton, L. W. Irwin, K. A. Peterson, M. T. Dugger, D. C. Senft, N. F. Smith, P. Tangyunyong, and S. L. Miller, "The Effect of Frequency on the Lifetime of a Surface Micromachined Microengine Driving a Load," IEEE International Reliability Physics Symposium, Reno, NV, 1998, pp. 26-35.

[8] E. J. Garcia and J. J. Sniegowski, "Surface micromachined microengine", Sensors and Actuators A, Vol. 48, 1995, pp. 203214.

[9] D. M. Tanner, K. A. Peterson, L. W. Irwin, P. Tangyunyong, W. M. Miller, W. P. Eaton, N. F. Smith, M. S. Rodgers, "Linkage Design Effect on the Reliability of Surface Micromachined Microengines Driving a Load," Proceedings of SPIE, Vol. 3512, pp. 215-226.

[10] R. Maboudian and R. T. Howe, "Critical Review: Adhesion in surface micromechanic structures," Journal Vac. Sci. Technol., B 15(1), Jan/Feb 1997, pp. 1-20.

[11] R. Maboudian and R. T. Howe, "Stiction reduction processes for surface micromachines," Tribology Letters, 3, 1997, pp. 215-221.

[12] M. R. Houston, R. T. Howe, and R. Maboudian, in $8^{\text {th }}$ Int. Conf. On Solid-State Sensors and Actuators (Transducers '95) and Eurosensors IX, Vol.1 Stockholm, June 1995, pp. 210-213.

[13] R. L. Alley, R. T. Howe, and K. Komvopoulos, Proceedings of the IEEE Solid-State Sensor and Actuator Workshop, Hilton Head, SC, 1992, pp. 202-207.

[14] G. T. Mulhern, D. S. Soane, and R. T. Howe, in Proc. $7^{\text {th }}$ Int. Conf. on Solid-State Sensors and Actuators (Transducers '93), Yokohama, June 1993, pp.296-299.

[15] D. M. Tanner, N. F. Smith, D. J. Bowman, W. P. Eaton, K. A. Peterson, "First Reliability Test of a Surface Micromachined Microengine Using SHiMMeR," Proceedings SPIE Symposium on Micromachining and Microfabrication, Vol. 3224, Austin, 1997, pp 14-23.
[16] Paul A. Tobias and David Trindade, Applied Reliability, New York, Van Nostrand Reinhold, 1986, ch. 5, pp. 93-101.

[17] S. L. Miller, M. S. Rodgers, G. LaVigne, J. J. Sniegowski, P. Clews, D. M. Tanner, K. A. Peterson, "Failure Modes in Surface Micromachined MicroElectroMechanical Actuators," Proc. 1998 IEEE International Reliability Physics Symposium, Reno, NV, 1998, pp. 17-25.

[18] T. E. Fischer and W. M. Mullins, "Ceramics, friction, and chemistry," CHEMTECH, 23:2 (1993), pp. 27-31.

[19] U. Srinivasan, J. D. Foster, U. Habib, R. T. Howe, R. Maboudian, D. C. Senft, and M. T. Dugger, "Lubrication of Polysilicon Micromechanisms with Self-Assembled Monolayers," Proc. IEEE Solid-State Sensor Actuator Workshop, Hilton Head, SC, USA, 1998, pp. 156-161.

[20] J. Takadoum, Z. Zsiga, M. Ben Rhouma, and C. RoquesCarmes, "Correlation between friction coefficient and wear mechanism of SiC/SiC system," Journal of Material Science Letters, 13, 1994, pp. 474-476.

[21] M. G. Gee and D. Butterfield, "The combined effect of speed and humidity on the wear and friction of silicon nitride," Wear, 162-164, 1993, pp. 234-245.

[22] K. Mizuhara and S. M. Hsu, "Tribochemical Reaction of Oxygen and Water on Silicon Surfaces," Wear Particles, Elsevier Science Publishers (D. Dowson et. al. Editors), 1992, pp. 323328.

[23] E. S. Zanoria, S. Danyluk, and M. J. McNallan, "Formation of Cylindrical Sliding-Wear Debris on Silicon in Humid Conditions and Elevated Temperatures," Tribology Transactions, 38, 1995, pp.721-727.

[24] M. N. Gardos, "Advantages and Limitations of Silicon as a Bearing Material for MEMS Applications," Tribology Issues and Opportunities in MEMS, Kluwer Academic Publishers, Netherlands, ed. by B. Bhushan, 1998, pp. 341-365.

[25] E. Rabinowicz, Friction and Wear of Materials, New York, John Wiley \& Sons, Inc., 1995. 